\title{
Surgery for Congenital Heart Disease
}

\section{A prospective randomized study comparing volume-standardized modified and conventional ultrafiltration in pediatric cardiac surgery}

\author{
LeNardo D. Thompson, MD \\ Doff B. McElhinney, MD \\ Pauline Findlay, CCP \\ Wanda Miller-Hance, MD \\ Mark J. Chen, BS \\ Mariko Minami, BS \\ Ed Petrossian, MD \\ Andrew J. Parry, MD \\ V. Mohan Reddy, MD \\ Frank L. Hanley, MD
}

See related editorial on page 209.
Background: Modified ultrafiltration has been touted as superior to conventional ultrafiltration for attenuating the consequences of hemodilution after cardiac surgery with cardiopulmonary bypass in children. We conducted a prospective randomized study to test the hypothesis that modified and conventional ultrafiltration have similar clinical effects when a standardized volume of fluid is removed.

Methods: From October 1998 to September 1999, 110 children weighing $15 \mathrm{~kg}$ or less (median weight $6.1 \mathrm{~kg}$, median age 6.3 months) undergoing surgery with cardiopulmonary bypass for functionally biventricular congenital heart disease were randomized to conventional $(n=67)$ or arteriovenous modified ultrafiltration $(n=43)$ for hemoconcentration. The volume of fluid removed with both methods was standardized as a percentage of effective fluid balance (the sum of prime volume and volume added during cardiopulmonary bypass minus urine output): in patients weighing less than $10 \mathrm{~kg}$, $50 \%$ of effective fluid balance was removed, whereas $60 \%$ was removed in patients weighing 10 to $15 \mathrm{~kg}$. Hematocrit, hemodynamics, ventricular function, transfusion of blood products, and postoperative resource use were compared between groups.

Results: There were no significant differences between groups in age, weight, or duration of cardiopulmonary bypass. The total volume of fluid added in the prime and during bypass was greater in patients undergoing conventional ultrafiltration than in those receiving modified ultrafiltration $(205 \pm 123$ vs $162 \pm 74 \mathrm{~mL} / \mathrm{kg} ; P=$ .05 ), although the difference was due primarily to a greater indexed priming volume in patients having conventional ultrafiltration. There was no difference in the percentage of effective fluid balance that was removed in the 2 groups. Accordingly, the volume of ultrafiltrate was greater in patients receiving conventional than modified ultrafiltration ( $95 \pm 63$ vs $68 \pm 28 \mathrm{~mL} / \mathrm{kg} ; P=.01)$. Preoperative and postoperative hematocrit levels were $35.6 \% \pm 6.6 \%$ and $36.3 \% \pm 5.6 \%$ in patients having conventional ultrafiltration and $34.4 \% \pm 6.7 \%$ and $38.7 \% \pm 7.5 \%$ in those having modified ultrafiltration. By repeated-measures analysis of variance, patients receiving modified and conventional ultrafiltration did not differ with respect to hemat- 
ocrit value $(P=.87)$, mean arterial pressure $(P=.85)$, heart rate $(P=.43)$, or left ventricular shortening fraction $(P=.21)$ from baseline to the postbypass measurements. There were no differences between groups in duration of mechanical ventilation, stay in the intensive care unit, or hospitalization.

Conclusions: When a standardized volume of fluid is removed, hematocrit, hemodynamics, ventricular function, requirement for blood products, and postoperative resource use do not differ between pediatric patients receiving conventional and modified ultrafiltration for hemoconcentration after cardiac surgery.

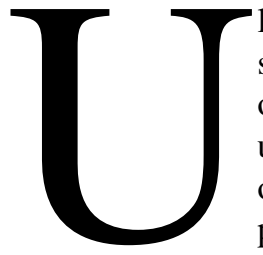

ltrafiltration has become an important strategy for mitigating the adverse effects of hemodilution that occur in children undergoing cardiac surgery with the use of cardiopulmonary bypass (CPB). In pediatric cardiac surgical practice, there are 2 basic approaches to ultrafiltration in wide use. ${ }^{1}$ Conventional ultrafiltration (CUF) involves ultrafiltration during the rewarming phase of CPB. Because the patient remains on $\mathrm{CPB}$, the volume of fluid removed with CUF may be limited by circuit volume, insofar as sufficient volume in the venous reservoir is necessary to ensure adequate arterial inflow. In contrast, modified ultrafiltration (MUF) is performed after discontinuation of $\mathrm{CPB}$ and is independent of circuit volume. Because of this technical difference, more fluid can often be removed with MUF than with CUF, assuming that no or minimal additional volume is added to the circuit during CUF. This difference may translate into greater efficacy in attenuating the deleterious effects of hemodilution. Although a number of studies have investigated the potential advantages of MUF, ${ }^{2-11}$ the issue of whether MUF has any intrinsic benefit over CUF aside from the potentially greater volume of fluid removed has not been investigated. To test the hypothesis that there is no benefit, we conducted a prospective randomized study comparing the effects of MUF and CUF in infants and young children when a standardized volume of fluid is removed during the ultrafiltration process. The results of this investigation are described in the present report.

\section{Patients and Methods \\ Patients}

Between October 1998 and September 1999, 110 patients weighing $15 \mathrm{~kg}$ or less undergoing surgery for biventricular congenital heart disease with the use of $\mathrm{CPB}$ were enrolled prospectively. The study was conducted at 3 hospitals staffed by surgeons from our group: University of California at San Francisco Medical Center, Valley Children's Hospital in Fresno, and Children's Hospital of Oakland, with the same methods of CPB and ultrafiltration used at all 3 centers. Exclusion criteria included preoperative mechanical ventilatory support and ongoing corticosteroid therapy for any reason. Patients were randomized to surgery with CUF $(n=67)$ or MUF ( $n=43)$, with separate randomization at each site. A wide range of functionally biventricular heart defects was represented, with the majority of patients in both groups having atrial septal defect, ventricular septal defect, tetralogy of Fallot, or transposition of the great arteries.

\section{Cardiopulmonary Bypass}

Our standard pediatric perfusion protocol was used in all patients, with aortic and bicaval cannulation and flow rates of 125 to 200 $\mathrm{mL} \cdot \mathrm{kg}^{-1} \cdot \mathrm{min}^{-1}$, depending on weight, to maintain mixed venous oxygen saturations of $60 \%$ to $70 \%$. Blood prime was used, with priming volume determined by the sizes of arterial and venous tubing. Cold sanguineous crystalloid cardioplegic solution was used during aortic crossclamping. Circulatory arrest was not used.

\section{Ultrafiltration}

The volume of fluid removed with both CUF and MUF was standardized according to a set percentage of effective fluid balance. Effective fluid balance was defined as the sum of the priming volume and volume added during CPB (cardioplegic solution included), less urine output. In patients less than $10 \mathrm{~kg}$, the target ultrafiltrate volume was $50 \%$ of the effective fluid balance, and in patients weighing between 10 and $15 \mathrm{~kg}$, it was $60 \%$ of the effective fluid balance. With both MUF and CUF, a Hemocor HPH 400 Minntech hemofilter (Minntech Corporation, Minneapolis, Minn) was primed with Normosol R solution, $\mathrm{pH}$ 7.4.

During CUF, ultrafiltration was conducted during the rewarming phase of CPB. The hemofilter was connected by $1 / 4$-inch tubing to the venous reservoir, proximal to a roller pump head, which pulled blood from the venous reservoir through the hemofilter at a rate of 15 to $30 \mathrm{~mL} \cdot \mathrm{kg}^{-1} \cdot \mathrm{min}^{-1}$, returning the concentrated blood to the cardiotomy reservoir. The suction port to the hemoconcentrator was clamped until the target flow rate was reached; then suction was applied to the filtration port and regulated to a pressure up to $-180 \mathrm{~mm} \mathrm{Hg}$.

In the MUF group, arteriovenous MUF was performed after discontinuation of CPB until the goal volume of ultrafiltrate effluent was reached. Via a 1/4-inch recirculation line distal to the arterial filter, blood was pulled through a separate roller pump head, allowing for simultaneous ultrafiltration of the patient's blood and residual pump volume. Blood was pumped through the hemofilter and heat exchanger, with air trapping capacity to maintain a temperature of 
TABLE 1. Demographic variables in patients undergoing CUF and MUF

\begin{tabular}{lccc}
\hline Variable & CUF $(\mathbf{n}=\mathbf{6 7})$ & MUF $(\mathbf{n}=\mathbf{4 3})$ & $P$ value \\
\hline Age $(\mathrm{mo})$ & $9.0 \pm 11.3$ & $12.6 \pm 14.1$ & .15 \\
Weight $(\mathrm{kg})$ & $6.5 \pm 3.2$ & $7.7 \pm 3.2$ & .07 \\
Height $(\mathrm{cm})$ & $66 \pm 12$ & $66 \pm 22$ & .97 \\
\hline
\end{tabular}

$37^{\circ} \mathrm{C}$. The flow rate through the hemofilter and filtration suction pressure were the same as with CUF. The concentrated blood was returned to the right atrium through a single angled-tip venous cannula. Patients in the MUF group did not receive CUF.

\section{Data Analysis}

Perioperative data were collected prospectively and are expressed as median and range or mean \pm standard deviation unless otherwise specified. Odds ratios (OR) are presented with $95 \%$ confidence intervals $(95 \% \mathrm{CI})$. Comparison between patients who received MUF and those who received CUF was conducted with respect to preoperative, intraoperative, and postoperative variables including age, weight, height, duration of $\mathrm{CPB}$ and aortic crossclamping, heart rate, blood pressure, left ventricular shortening fraction, receipt of blood products (red blood cells, platelets, and plasma), chest tube drainage, duration of mechanical ventilatory support, duration of stay in the intensive care unit, and duration of hospitalization. For continuous variables comparing serial values after baseline measurements before $\mathrm{CPB}$, repeated-measures analysis of variance (ANOVA) was used. For comparison between CUF and MUF groups of dichotomous and continuous variables not measured serially, $\chi^{2}$ analysis and independent samples $t$ test were used, respectively. The software package SPSS for Windows version 7.0 (SPSS Inc, Chicago, Ill) was used for statistical analysis.

\section{Results \\ Patients}

Patients ranged in age from 1 day to 5 years (median 6.3 months), in weight from 2.4 to $15 \mathrm{~kg}$ (median $6.1 \mathrm{~kg}$ ), and in height from 23 to $100 \mathrm{~cm}$ (median $66 \mathrm{~cm}$ ). There was no significant difference in any of these variables between patients in the CUF and MUF groups, although patients undergoing MUF weighed more to a degree that approached significance (Table 1).

\section{CPB and Ultrafiltration}

There was no difference in duration of CPB $(119 \pm 54$ vs $118 \pm 46$ minutes; $P=.88)$ or aortic crossclamping $(53 \pm 34$ vs $51 \pm 34$ minutes; $P=.72$ ) between patients undergoing CUF and MUF.

The total indexed volume of fluid received in the pump prime and during CPB was significantly greater in patients undergoing CUF than those receiving MUF (Table 2). This difference was primarily due to a significantly larger relative prime volume in patients undergoing CUF. Although the indexed volume of fluid received during $\mathrm{CPB}$ was also larg- er in patients receiving CUF, this difference was not statistically significant (Table 2). Urine output during CPB did not differ between groups. The effective fluid balance, defined as total fluid received in the prime and during CPB minus urine output, was greater in patients undergoing CUF to a degree that approach statistical significance (Table 2). In both groups, an average of approximately 50\% of effective fluid balance was removed in the ultrafiltration effluent. The proportion of patients in whom $90 \%$ or more of the target ultrafiltration volume was removed (ie, $\geq 45 \%$ in patients $<10 \mathrm{~kg}, \geq 54 \%$ in patients between 10 and $15 \mathrm{~kg}$ ) was approximately $80 \%$, with no difference between CUF and MUF groups (Table 2).

\section{Hemodynamics and Ventricular Function}

There were no differences in heart rate between patients in the CUF and MUF groups at baseline, 10 minutes after completion of extracorporeal circulation (ie, CPB or ultrafiltration), or 1 hour after extracorporeal circulation. Likewise, the trend in heart rate across these time points did not differ between groups by repeated-measures ANOVA $(P$ $=.43$, Figure $1, A)$. Mean arterial blood pressure was lower at baseline and 10 minutes after CPB in the CUF group but did not differ significantly 1 hour after CPB or across time by repeated-measures ANOVA $(P=.85$, Figure $1, B)$. Left ventricular shortening fraction did not differ between CUF and MUF patients at baseline, immediately after extracorporeal circulation, or 10 minutes after extracorporeal circulation, nor was there a difference in the trend over time by repeated-measured ANOVA $(P=.21$, Figure $1, C)$.

\section{Blood Requirement and Postoperative Resource Use}

No difference in baseline hematocrit value was apparent between patients undergoing CUF and MUF $(P=.40)$, and there was a trend toward a higher hematocrit value after discontinuation of ultrafiltration in the MUF group $(P=.08$; Figure 2). In patients undergoing MUF, the hematocrit value immediately before ultrafiltration (after CPB) was significantly lower than at baseline $(34.4 \% \pm 6.7 \%$ vs $28.1 \% \pm$ $6.4 \% ; P<.001)$, and there was a significant increase in hematocrit from the initiation to the completion of MUF $(28.1 \% \pm 6.4 \%$ vs $38.7 \% \pm 7.5 \% ; P<.001)$. The hematocrit value after MUF was significantly higher than at baseline (Figure 2). In patients undergoing CUF, the hematocrit value after discontinuation of CPB did not differ significantly from baseline (Figure 2). By repeated-measures ANOVA, however, there was no difference between CUF and MUF groups in the change in hematocrit value from baseline to post-ultrafiltration measurements $(P=.87)$.

No difference existed between CUF and MUF groups in the indexed volume of packed red blood cells and whole blood in the CPB prime or in the total blood received in the operating room (including that in the prime and that admin- 

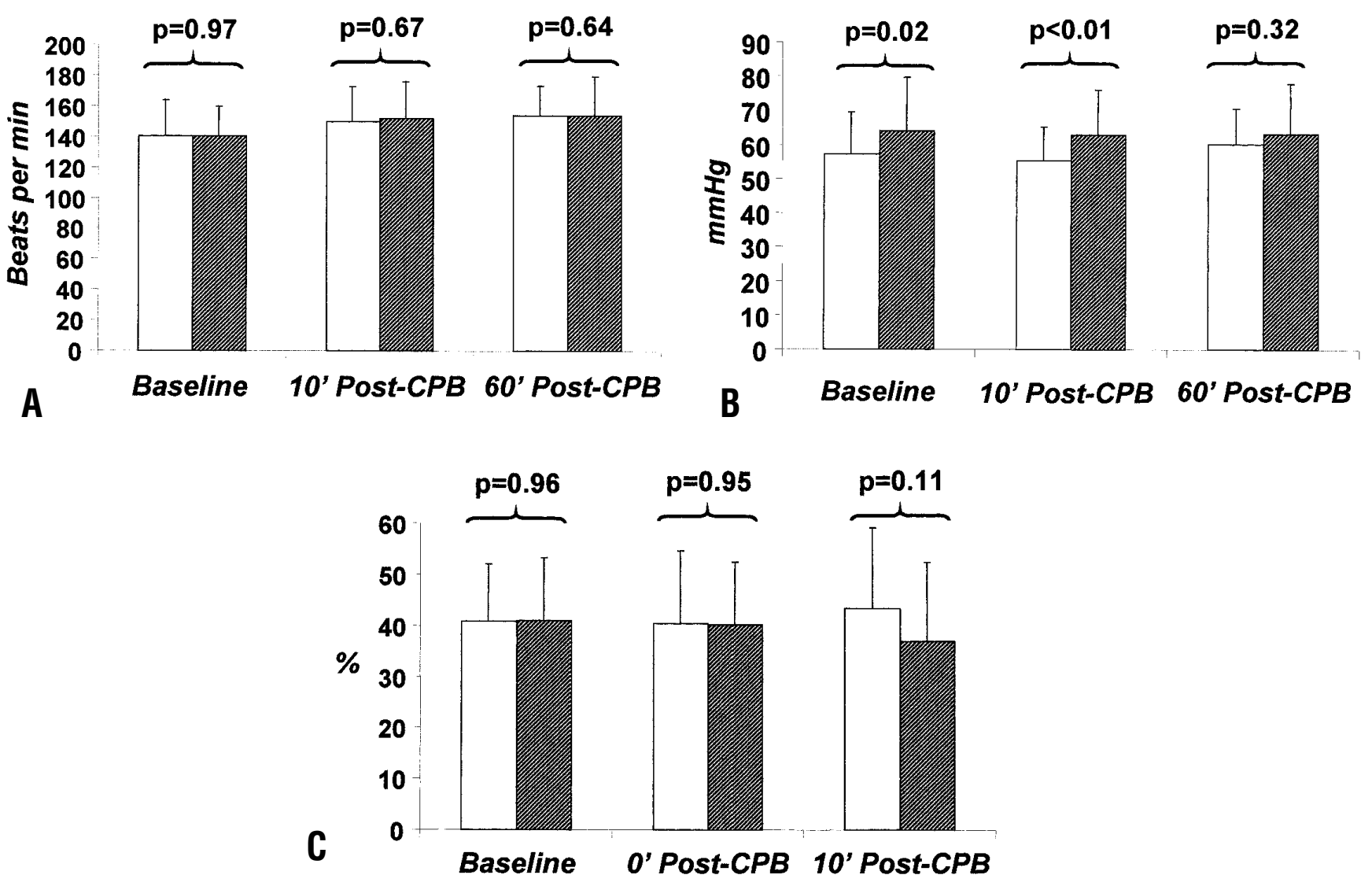

Figure 1. Hemodynamics and ventricular function in patients undergoing hemoconcentration with CUF (white bars) and MUF (hatched bars). A, Heart rate before CPB (baseline), 10 minutes after the discontinuation of CPB (CUF group) or ultrafiltration (MUF group), and 1 hour after CPB/ultrafiltration. B, Mean arterial blood pressure at the same time points. C, Left ventricular shortening fraction determined by transesophageal echocardiography before CPB, at the discontinuation of $\mathrm{CPB} /$ ultrafiltration, and 10 minutes after $\mathrm{CPB} /$ ultrafiltration. $P$ values depicted are for independent samples $t$ test comparison of CUF and MUF at each time point. Trends over time did not differ significantly by repeated-measures ANOVA (see text).

istered during CPB) (Figure 3). During the first 48 hours after surgery, there was no difference between groups in the indexed volume of blood transfused (Figure 3).

No differences were found between groups in the proportion of patients who received platelet transfusions (CUF $28 \%$ vs MUF $32 \%$; OR $=0.84 ; 95 \% \mathrm{CI}=0.37-1.9 ; P=.68)$ or fresh frozen plasma (CUF $82 \%$ vs MUF $70 \%$; OR $=1.9$; $95 \% \mathrm{CI}=0.79-4.8 ; P=.14)$ postoperatively, and no differences were observed in the volume of these products transfused in those who did receive them (platelets: $12.8 \pm 4.9 \mathrm{vs}$ $12.0 \pm 3.8 \mathrm{~mL} / \mathrm{kg} ; P=.62$; plasma: $20.4 \pm 9.1$ vs $18.4 \pm 6.6$ $\mathrm{mL} / \mathrm{kg} ; P=.28$ ). Chest tube drainage during the first 48 hours after surgery was greater in patients randomized to MUF than those who received CUF (Table 2).

The durations of postoperative mechanical ventilatory support, stay in the intensive care unit, and hospitalization did not differ between patients undergoing CUF and MUF (Table 3).

\section{Discussion}

CPB is a double-edged sword. Without it, corrective cardiac surgery would not be possible in the majority of children with congenital heart disease. However, much of the perioperative morbidity that occurs after cardiac surgery can be attributed in large part to pathophysiologic processes engendered by extracorporeal circulation. ${ }^{12}$ One of the challenges that has confronted practitioners of pediatric cardiac surgery has been to minimize the consequences of CPB. Ultrafiltration is a strategy that has been used for many years in an effort to attenuate the effects of hemodilution that occur when small children undergo surgery with CPB. Over the past several years, a modified technique of ultrafiltration, commonly known as MUF, has been used with increasing enthusiasm. When Naik, Knight, and Elliott ${ }^{2}$ first applied this strategy of ultrafiltration after discontinuation of $\mathrm{CPB}$, the basis of their 


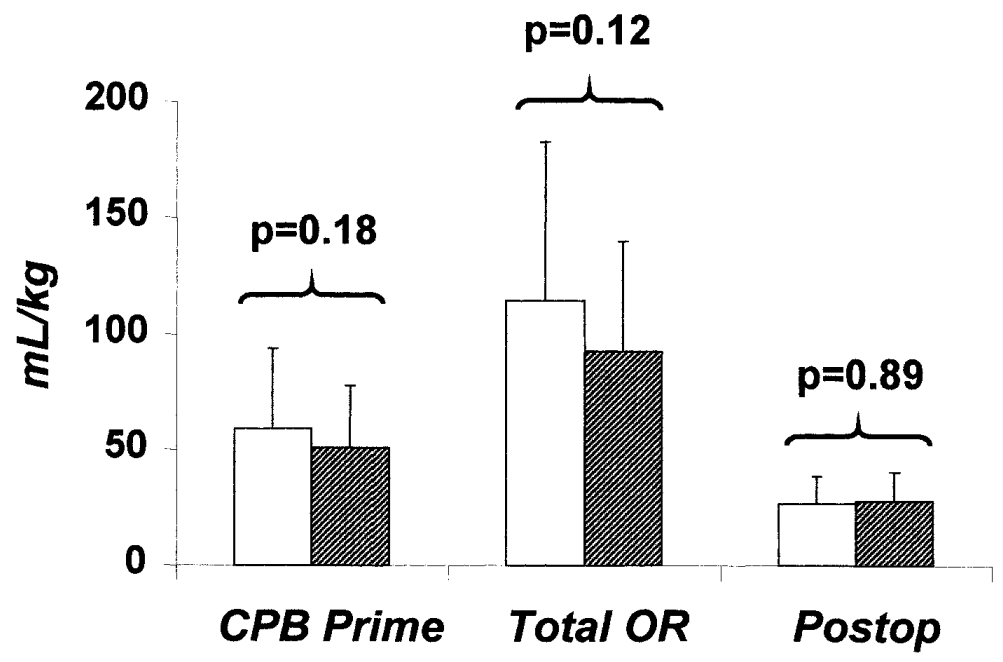

Figure 2. Packed red blood cells and whole blood received in patients undergoing CUF (white bars) and MUF (hatched bars) in the CPB priming solution, in the operating room (OR) (in the prime and during CPB), and over the first 48 hours postoperatively. $P$ values depicted are for independent samples $t$ test comparison of CUF and MUF at each time point.

TABLE 2. Fluid and ultrafiltration data in patients undergoing CUF and MUF

\begin{tabular}{|c|c|c|c|}
\hline Variable & CUF $(n=67)$ & MUF (n= 43) & $P$ value \\
\hline Total fluid received in prime and during CPB $(\mathrm{mL} / \mathrm{kg})$ & $205 \pm 123$ & $162 \pm 74$ & .05 \\
\hline Priming volume $(\mathrm{mL} / \mathrm{kg})$ & $106 \pm 51$ & $87 \pm 36$ & .04 \\
\hline Fluid added during CPB $(\mathrm{mL} / \mathrm{kg})$ & $102 \pm 86$ & $80 \pm 48$ & .55 \\
\hline Urine output on CPB (mL/kg) & $11 \pm 17$ & $12 \pm 20$ & .87 \\
\hline Effective fluid balance $(\mathrm{mL} / \mathrm{kg})$ & $189 \pm 112$ & $154 \pm 70$ & .09 \\
\hline Ultrafiltrate volume $(\mathrm{mL} / \mathrm{kg})$ & $96 \pm 63$ & $69 \pm 28$ & .01 \\
\hline Percent effective fluid balance filtered & $50 \pm 13$ & $47 \pm 11$ & .23 \\
\hline Percent of patients within $10 \%$ of goal ultrafiltrate volume* & 82 & 78 & .45 \\
\hline Chest tube drainage during the first 48 hours after surgery $(\mathrm{mL} / \mathrm{kg})$ & $17.8 \pm 7.0$ & $26.6 \pm 11.0$ & $<.001$ \\
\hline
\end{tabular}

${ }^{*}$ As defined in the methods section.

TABLE 3. Postoperative resource use in patients undergoing CUF and MUF

\begin{tabular}{lccc}
\hline Variable & CUF $(\mathbf{n}=\mathbf{6 7})$ & MUF $(\mathbf{n}=\mathbf{4 3})$ & $P$ value \\
\hline Duration of mechanical ventilation (d) & $2.6 \pm 1.4$ & $2.5 \pm 0.9$ & .82 \\
Duration of intensive care unit stay (d) & $4.6 \pm 1.8$ & $5.0 \pm 1.5$ & .21 \\
Duration of postoperative hospitalization (d) & $6.5 \pm 1.4$ & $7.0 \pm 1.6$ & .09
\end{tabular}

approach was the removal of a greater volume of fluid than they had been able to achieve with CUF.

Since this modified technique of post-CPB arteriovenous ultrafiltration was initially reported in 1991, a number of investigations have been performed on the effects of MUF in human children undergoing cardiac surgery with $\mathrm{CPB} .{ }^{2-11}$ The purported benefits of MUF shown in these studies, usually in comparison with patients not receiving any ultrafiltration, include the following: decreased total body water, ${ }^{2}$ higher systemic arterial blood pressure, ${ }^{2,3}$ decreased duration of postop- erative inotropic support, ${ }^{6}$ improved preload recruitable stroke work, ${ }^{6}$ improved oxygenation, ${ }^{5}$ better pulmonary compliance, ${ }^{9}$ decreased duration of ventilatory support, ${ }^{5}$ higher postoperative hematocrit value, $3,7,8$ lower postoperative blood $\operatorname{loss}^{2,3}$ and requirement for blood transfusion, 2,4,5,7,10 higher concentrations of plasma proteins and fibrinogen, ${ }^{8}$ less production of thromboxane $\mathrm{B}_{2}{ }^{11}$ and activation of complement, ${ }^{4}$ decreased pleural effusions, ${ }^{5,10}$ and shorter duration of hospitalization. $^{10}$ Other studies have documented removal of vasoactive substances and inflammatory cytokines in the efflu- 
ent from ultrafiltration, ${ }^{13}$ and animal studies have demonstrated other potential benefits of MUF. ${ }^{14,15}$ Despite this mounting evidence in support of a strategy of aggressive fluid removal, these reports supply little information about MUF as a technique, relative to the technique of CUF, and the only clear benefit of MUF over CUF remains the ability to remove a greater volume of fluid without giving additional crystalloid solution or blood.

In the present study, we tested the hypothesis that CUF and MUF will not differ in their clinical effects when a standardized volume of fluid is removed on the basis of patient weight and the volume added in the prime and during CPB. Our findings support this hypothesis. Patients randomized to volume-standardized CUF did not differ from those randomized to volume-standardized MUF with respect to efficacy of hemoconcentration (ie, pre-CPB vs post-CPB hematocrit), requirement for postoperative blood products, hemodynamics, ventricular function, duration of mechanical ventilation, or duration of the stay in the intensive care unit and hospital. Patients undergoing CUF did have a greater indexed volume of fluid removed during ultrafiltration, but there was no difference in the percentage of effective fluid balance that was removed. Rather, the difference in ultrafiltrate volume was a function of a greater indexed prime volume in patients undergoing CUF.

Inherent in any study of ultrafiltration is the problem of standardization and comparability. Namely, CUF and MUF are both nonuniform practices, which typically differ from center to center. With respect to this issue, it is important to acknowledge that CUF and MUF should be considered both techniques and strategies. As a technique, MUF involves ultrafiltration after discontinuation of $\mathrm{CPB}$, using either arteriovenous or venovenous filtration, whereas CUF is performed during the rewarming phase of CPB. An important technical difference between CUF and MUF is that, whereas CUF is performed during CPB and is therefore integrated into the perfusion routine with no additional time or risk, MUF necessitates an additional period of extracorporeal circulation at an important juncture in the operation. As strategies, MUF and CUF are represented by a wide spectrum of practices. The most significant variable is the aggressiveness with which hemoconcentration is pursued or, in other words, with which fluid is removed. A greater volume of fluid can often be removed with aggressive MUF than with CUF, assuming that no additional fluid is added to the CPB circuit during CUF, and this may have a significant effect on the clinical impact of ultrafiltration.

In the present study, we standardized the strategies of CUF and MUF by regulating the volume of fluid removed on the basis of patient weight and the total volume of fluid added during CPB (including priming and cardioplegic solutions). The purpose of this design was to compare CUF and MUF as techniques, without the confounding effect of

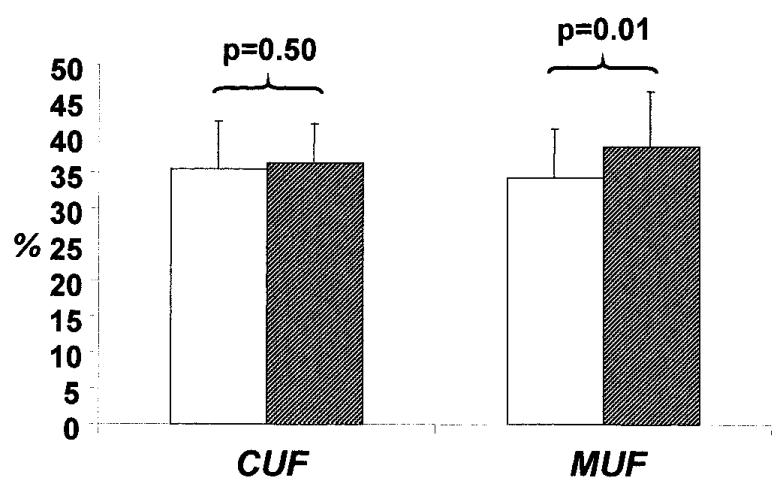

Figure 3. Hematocrit value before CPB (white bars) and after discontinuation of $\mathrm{CPB} /$ ultrafiltration (hatched bars) in patients undergoing hemoconcentration with CUF and MUF. $P$ values depicted are for independent samples $t$ test comparison of preCPB and post-CPB hematocrit for CUF and MUF groups, respectively. Trends over time did not differ significantly by repeatedmeasures ANOVA (see text).

differences in strategy. It might be argued that the volumestandardized MUF performed in our study was not truly MUF, inasmuch as the volume of fluid removed was limited. This is a troublesome objection, because it begs the question, "What is MUF?" Clearly, our technique was that of arteriovenous MUF, and even though the volumestandardized method that we used may have been less aggressive than the approach to MUF at many centers, the mean increase in hematocrit value after MUF in our patients was 10 points (ie, from $28 \%$ to $38 \%$ ), indicating substantial hemoconcentration. However, this is an issue of strategy rather than technique, and there are numerous strategies of MUF, not to mention ultrafiltration altogether. Ultimately, we do not think that the volume-standardized design detracts from our study, for, to reiterate, strategies of ultrafiltration are incredibly variable and our objective was to compare techniques rather than strategies.

The optimal approach to ultrafiltration in infants and young children undergoing cardiac surgery with $\mathrm{CPB}$ remains uncertain. The deleterious effects of CPB likely begin in the very early stages of extracorporeal circulation. Thus, although ultrafiltration during rewarming and after $\mathrm{CPB}$ may attenuate the pathophysiologic processes engendered by $\mathrm{CPB}$, it will not prevent them altogether. Although ultrafiltration can remove cytokines involved in the pathophysiologic cascades resulting from CPB, it is not clear that this mechanism, as opposed to the simple removal of extra fluid, translates into improved clinical outcome, as discussed in a recent article by Ramamoorthy and Lynn. ${ }^{16}$ The kinetics of CPB-related cytokine elaboration and complement activation have not been well characterized, nor has the issue of when in the course of this process removal of such substances by ultrafiltration can be expected to result in a meaningful reduction in the systemic 
inflammatory response to CPB. Regardless, it is likely that the earlier ultrafiltration-or removal of vasoactive substances and cytokines by other means - is initiated, the more effective such measures will be. CUF during rewarming or earlier initiation of ultrafiltration with zero-balance ultrafiltration (not investigated in the present report) at the initiation of CPB are likely beneficial even if aggressive MUF is used after CPB.

Strategies of ultrafiltration need not be either/or, as the various techniques may be used separately or in combination. Different centers use MUF and CUF differently, with varying strategies and goals. If the goal is simply to achieve effective hemoconcentration, aggressive MUF alone may be adequate, as may aggressive CUF. However, if the objective is to reap the maximum benefit of ultrafiltration, including both hemoconcentration and removal of vasoactive and chemoactive substances elaborated in response to CPB, it is likely that earlier initiation of ultrafiltration is advisable. In one of the few studies to compare combined ultrafiltration during CPB (zero-balance ultrafiltration in this case) and MUF with MUF alone, Journois and associates ${ }^{17}$ observed superior hemostasis and ventilatory function in patients undergoing both. Such data, and the general lack of clarity regarding the optimal strategy of ultrafiltration after cardiac surgery in children, highlight the need for further studies into the optimal approach to hemoconcentration in the pediatric population. The present study demonstrates that CUF and MUF are not substantially different from a technical point of view. The question of optimal ultrafiltration strategy remains open.

\section{References}

1. Pouard P, Journois J, Greeley WJ. Hemofiltration and pediatric cardiac surgery. In: Greeley WJ, editor. Perioperative management of the patient with congenital heart disease. Baltimore: Williams \& Wilkins; 1996. p. 121-32.

2. Naik SK, Knight A, Elliott M. A prospective randomized study of a modified technique of ultrafiltration during pediatric open-heart surgery. Circulation. 1991;84(Suppl):III-422-31.

3. Ad N, Snir E, Katk J, Birk E, Vidne BA. Use of the modified technique of ultrafiltration in pediatric open-heart surgery: a prospective study. Isr J Med Sci. 1996;32:1326-31.

4. Andreasson S, Gothberg S, Berggren H, Bengtsoon A, Erikson E, Risburg B. Hemofiltration modifies complement activation after extracorporeal circulation in infants. Ann Thorac Surg. 1993;56:1515-7.

5. Bando K, Turrentine MW, Vijay P, Sharp TG, Sekine Y, Lalone BJ, et al. Effect of modified ultrafiltration in high-risk patients undergoing operations for congenital heart disease. Ann Thorac Surg. 1998;66:821-8.

6. Davies MJ, Nguyen K, Gaynor JW, Elliott MJ. Modified ultrafiltration improves left ventricular systolic function in infants after cardiopulmonary bypass. J Thorac Cardiovasc Surg. 1998;115:361-70.

7. Friesen RH, Campbell DN, Clarke DR, Tornabene MA. Modified ultrafiltration attenuates dilutional coagulopathy in pediatric open heart operations. Ann Thorac Surg. 1997;64:1787-9.

8. Gurbuz AT, Novick WM, Pierce CA, Watson DC. Impact of ultrafiltration on blood use for atrial septal defect closure in infants and children. Ann Thorac Surg. 1998;65:1105-9.
9. Keenan HT, Thiagarajan R, Stephens KE, Williams G, Ramamoorthy C, Lupinetti FM. Pulmonary function after modified venovenous ultrafiltration in infants: a prospective, randomized trial. $J$ Thorac Cardiovasc Surg. 2000;119:501-7.

10. Koutlas TC, Gaynor JW, Nicolson SC, Steven JM, Wernovsky G, Spray TL. Modified ultrafiltration reduces postoperative morbidity after cavopulmonary connection. Ann Thorac Surg. 1997;64:37-43.

11. Pearl JM, Manning PB, McNamara JL, Saucier MM, Thomas DW. Effect of modified ultrafiltration on plasma thromboxane B2, leukotriene B4, and endothelin-1 in infants undergoing cardiopulmonary bypass. Ann Thorac Surg. 1999;68:1369-75.

12. Miller B, Levy J. The inflammatory response to cardiopulmonary bypass. J Thorac Cardiovasc Anesth. 1997;11:355-66.

13. Wang MJ, Chiu IS, Hsu CM, Wang CM, Lin PL, Chang CI, et al. Efficacy of ultrafiltration in removing inflammatory mediators during pediatric cardiac operations. Ann Thorac Surg. 1996;61:651-6.

14. Skaryak LA, Kirshbom PM, DiBernardo LR, Kern FH, Greeley WJ, Ungerleider RM, et al. Modified ultrafiltration improves cerebral metabolic recovery after circulatory arrest. J Thorac Cardiovasc Surg. 1995; 109:744-52.

15. Daggett CW, Lodge AJ, Scarborough JE, Chai PJ, Jaggers J, Ungerleider RM. Modified ultrafiltration versus conventional ultrafiltration: a randomized prospective study in neonatal piglets. $J$ Thorac Cardiovasc Surg. 1998;115:336-42.

16. Ramamoorthy C, Lynn AM. Con: the use of modified ultrafiltration during pediatric cardiovascular surgery is not a benefit. J Cardiothorac Vasc Anesth. 1998;12:483-5.

17. Journois D, Israel-Biet D, Pouard P, Rolland B, Silvester W, Vouhé P, et al. High-volume, zero-balanced hemofiltration to reduce delayed inflammatory response to cardiopulmonary bypass in children. Anesthesiology. 1996;85:965-76.

\section{Discussion}

Dr William Gaynor (Philadelphia, $\mathrm{Pa}$ ). In this study, the authors assessed the effects of ultrafiltration during or after CPB in children. In both groups ultrafiltration was terminated after a predetermined volume of fluid was removed. Because of this study design, it is not surprising that the authors found no significant differences between the groups in hematocrit values, hemodynamic parameters, or postoperative course.

The use of ultrafiltration after CPB, or MUF, was introduced by Martin Elliott and his associates in London to ameliorate some of the adverse effects of CPB and because of the limited ability of ultrafiltration during bypass to remove fluid and prevent the increase in total body water.

The use of ultrafiltration (or MUF) after CPB has been shown to be significantly more effective than ultrafiltration during bypass (or CUF) in reducing the increase in total body water after bypass. This is not due to any special effect of MUF but rather to the ability, as the authors note, to remove a greater volume of filtrate in the post-CPB period. Use of MUF results in significant improvements in cardiac index and systolic blood pressure with a decrease in pulmonary vascular resistance, and these have been shown to correlate in a linear fashion with the fluid removal and the degree of hemoconcentration. In an animal study, the use of CUF was shown to prevent neither weight gain during CPB nor myocardial edema and did not improve hemodynamic parameters, whereas the use of MUF significantly reduced both weight gain and myocardial edema.

In addition, when the concentrations of inflammatory mediators in the ultrafiltrate are examined, there is no difference in the ultrafiltrate between CUF and MUF; however, because the volume 
of ultrafiltrate removed is significantly greater with MUF, removal of mediators is significantly greater.

A variety of criteria have been suggested for termination of MUF, including a target hematocrit value, complete salvage of circuit contents, and a time end point with an MUF duration of 15 to 20 minutes. A survey of perfusion practices at 22 centers using MUF revealed that $45 \%$ performed MUF until the circuit contents were completely salvaged, $23 \%$ used a time criterion, $18 \%$ used a combination of parameters, and only 1 based termination of MUF on removal of a predetermined volume of filtrate.

Considerable controversy remains over the optimal method for use of ultrafiltration during and after CPB in infants. At Children's Hospital of Philadelphia, we aggressively use both CUF and MUF in all neonates and infants, including those undergoing staged reconstruction for hypoplastic left heart syndrome. In an 18-month period, MUF was performed in 467 patients weighing less than 15 $\mathrm{kg}$, at a median age of 4 months and a median weight of $5 \mathrm{~kg}$. CUF was used in $87 \%$ of these patients. MUF is continued until the circuit contents have been completely salvaged. The mean volume of filtrate removed was $130 \mathrm{~mL} / \mathrm{kg}$ and was greater than $100 \mathrm{~mL} / \mathrm{kg}$ in $65 \%$ of the patients and greater than $150 \mathrm{~mL} / \mathrm{kg}$ in $30 \%$. The hematocrit value at the termination of bypass was $25 \%$ and increased to $40 \%$. The mean duration of MUF was 12 minutes, and there were no MUF-related complications.

I have several questions for the authors.

As this was a prospective randomized study, why was the CUF group so much larger than the MUF group? Also, were the diagnoses and procedures performed distributed equally between the groups?

How was the volume of filtrate to be removed determined? Was this based on a preliminary study of efficacy or simply an arbitrary value that was chosen?

What was the hematocrit value at the time of separation from $\mathrm{CPB}$ in the patients undergoing MUF? Did MUF result in an increase in hematocrit? If no increase in hematocrit is seen, it is unlikely to see a positive benefit.

Since the authors now agree that MUF is more effective than CUF at removal of fluid after CPB, have they altered their technique and use of ultrafiltration during and after CPB?

Dr Thompson. Regarding the distribution of patients between the MUF and CUF groups, this was a prospective randomized study and that is just the way our numbers turned out. Perhaps if we had done 200 cases the distribution would have evened out, but we are reporting the figures that we obtained.

We did preliminarily look at the volume and determine how much fluid we could remove from these patients rather than trying to remove as much as we possibly could. If you are going to standardize the volume, you have to determine a percentage and not just remove fluid arbitrarily.

Have we changed our approach to ultrafiltration? We individualize these patients according to what type of disease process they have, how long it is going to take to repair the defects, and whether we need to have some supplemental ultrafiltration in the patients.

We are not trying to convince anyone that MUF is bad. However, there is nothing magical about MUF. We are just saying that it is no different from CUF as a technique. Strategy is a different issue.
Dr Roger B. B. Mee (Cleveland, Ohio). Could I clarify one thing? At the point of termination of CPB for the 2 groups, what was the comparison of hematocrit values?

Dr Thompson. Hematocrit value was lower in the patients that had MUF before removal of the fluid, but immediately after MUF it was no different from CUF patients.

Dr Constantine Mavroudis (Chicago, Ill). Like many of us who do use MUF, I think you are wrong. I feel like I'm that old, gray-haired senator sitting in the back being explained why the Vietnam War was good. And he said, "I just can't believe it, but I see all these statistics."

I do not have any data to refute what you have to say, but I think it is wrong, and I will tell you why. Your data are not nearly as good as Martin Elliott's data. Don't you agree? He used unprecedented ventricular function studies by inflow inclusion and so on, and that was a study for the ages. You say that you have hemodynamic evidence that there is no difference between CUF and MUF, but you really do not have hemodynamic evidence. You have a few echocardiograms, but you do not have hemodynamic evidence to the extent that Martin Elliott's study has.

Furthermore, there are a couple of things that not even Martin studied. For instance, when you do ultrafiltration and you hemoconcentrate the patient, what are you doing to that dopamine and dobutamine that you have running? You did not account for that in your analysis. Will all the patients have 5 and 5 of dopamine and dobutamine or 5 of dobutamine? Did they have 3? And so forth.

You may say that it does not matter because you are prospectively randomizing these patients: One of them is CUF and another is MUF. However, if your groups were different in the amount of pressure agents they were getting at the start of the MUF, that would definitely affect your results.

Your study was well conceived. I guess I would have added a third arm - both MUF and CUF. I think one of the reasons your paper was included in this program is that it is controversial, and it provoked a good discussion.

Dr Thompson. What I was trying to do is look at a clinical outcome in a study that was conservatively done, without bias if possible.

There was no increase in inotropic agents, and the requirement for inotropic agents for both groups was about the same when we looked at it, so I cannot say that your statement is wrong. What I am trying to do is show you the data that I have.

Dr Marshall Jacobs (Philadelphia, $\mathrm{Pa}$ ). Had you not presented both strategies as having as their primary purpose hemoconcentration, I would not ask this question, because if you were going to talk about removal of cytokines and myocardial depressant factors, I think that the issues are very different. However, if the primary motivation for a strategy of ultrafiltration is hemoconcentration, I would simply suggest planning the bypass prime such that the hematocrit value is between $26 \%$ and $30 \%$. There is some experimental evidence, at least in part from Dr Jonas' laboratory, that may enhance cerebral protection. It does not alter blood use a great deal. In the vast majority of cases, we manage these patients without the use of ultrafiltration. We use it in perhaps in no more than $10 \%$ of cases with comparable clinical outcome.

Although I have no objections to ultrafiltration, I think if you select a predetermined hematocrit value of $18 \%$, then you make 
your choice between the two forms of ultrafiltration. If you select a hematocrit value on bypass that is considerably higher, you may not have to use either tool.

Dr Thompson. MUF is actually labor intensive. We must pay close attention while the patient is being subjected to MUF. After we do these complex cases, we think that the surgeon's attention to the postoperative hemodynamics and to bleeding or other technical aspects of the operation is very important. For that reason, MUF sometimes can be very cumbersome to use.
However, I do not think MUF is overly cumbersome in complex cases in which the patient is going to be difficult to wean from CPB because of fluid overload. Then MUF might be helpful in removing the excess water from those patients. Ultimately, the decision is one that requires a risk-benefit assessment.

Our study was not meant to measure myocardial edema and swelling. It was meant to determine whether clinical outcome differed between patients receiving CUF and those receiving MUF.

Access to The Journal of Thoracic and Cardiovascular Surgery Online is reserved for print subscribers!

Full-text access to The Journal of Thoracic and Cardiovascular Surgery Online is available for all print subscribers. To activate your individual online subscription, please visit The Journal of Thoracic and Cardiovascular Surgery Online, point your browser to http://www.mosby.com/jtcvs, follow the prompts to activate your online access, and follow the instructions. To activate your account, you will need your subscriber account number, which you can find on your mailing label (note: the number of digits in your subscriber account number varies from 6 to 10 ). See the example below in which the subscriber account number has been circled:

\section{Sample mailing label}

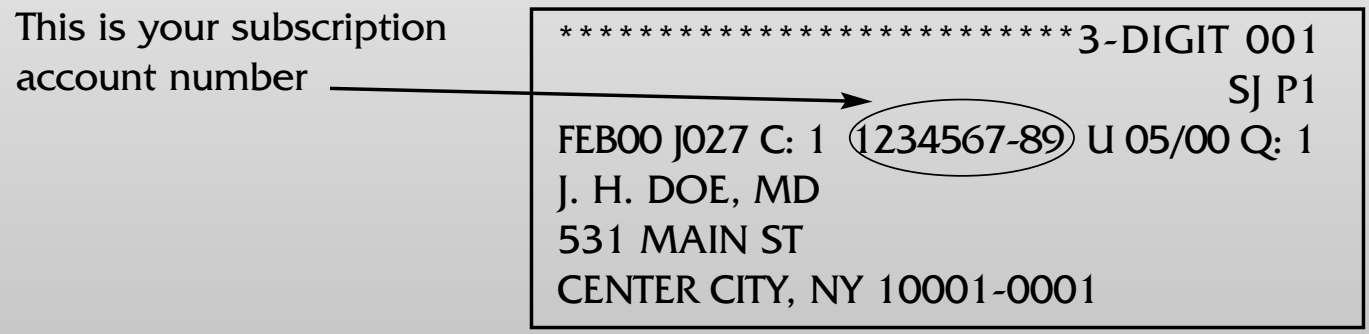

Personal subscriptions to The Journal of Thoracic and Cardiovascular Surgery Online are for individual use only and may not be transferred. Use of The Journal of Thoracic and Cardiovascular Surgery Online is subject to agreement to the terms and conditions as indicated online. 